14.3

\title{
Экранировка протекторных воздействий при лазерном облучении биообъектов: экспериментальные результаты и физическая модель
}

\author{
() А.А. Кокая, ${ }^{1}$ В.П. Козяков, ${ }^{1}$ Т.Э. Кулешова, ${ }^{2}$ Л.Н. Галль, ${ }^{3}$ Н.Р. Галль ${ }^{2,3, q}$ \\ ${ }^{1}$ Научно-исследовательский институт гигиены, профпатологии и экологии человека ФМБА России, \\ 188663 Ленинградская обл., Россия \\ 2 Физико-технический институт им. А.Ф. Иофрфе РАН, \\ 194021 Санкт-Петербург, Россия \\ ${ }^{3}$ Институт аналитического приборостроения РАН, \\ 198095 Санкт-Петербург, Россия \\ I e-mail: gall@ms.ioffe.ru
}

(Поступило в Редакцию 15 января 2018 г.)

Экспериментально изучены экранировки протекторных излучений, возникающих при лазерном облучении биологических тканей. Для экранировки использованы металлические и диэлектрические экраны различной формы. Предложена физическая модель генерации вторичного излучения, вызывающего протекторные эффекты, приводящие к существенному повышению устойчивости живых организмов, находящихся вблизи, к неблагоприятным внешним воздействиям. Выдвинуто предположение, что это излучение в основном сконцентрировано в области спектра ниже $10 \mathrm{GHz}$.

DOI: $10.21883 / J T F .2018 .09 .46430 .20-18$

\section{Введение}

Уникальные возможности лазеров в качестве источников когерентного излучения в широком диапазоне его частот и интенсивностей в настоящее время активно используются как в различных областях медицины, так и в биологических исследованиях. В медицине высокоинтенсивное лазерное излучение легло в основу ее нового направления - лазерной хирургии, а низкоинтенсивное излучение нашло свое применение в терапии и лазерной диагностике. Приоритет в медицинском применении лазеров принадлежит науке СССР [1], и научные исследования в этом направлении успешно продолжаются в России в настоящее время [2,3].

Не менее значимыми являются биологические исследования живых организмов с использованием лазеров, проводимые как с животными, так и с растениями [4]. Эти исследования, как правило, посвящены поиску условий, обеспечивающих повышение устойчивости живых объектов облучения к неблагоприятным воздействиям различной природы, и выяснению механизмов биологического действия лазеров. Обычно биологические исследования проводятся в области низких интенсивностей лазерного излучения. В медицине широко известны эффекты, в которых лазерное облучение вызывает выздоровление больных и оказывает стимулирующее и протекторное воздействие на здоровых людей и высших животных. Как правило, такие воздействия носят опосредованный характер: действию излучения подвергается не сам больной орган или организм, а близко расположенная к нему поверхность тела. В медицине этот метод активно применяется при лечении травматических и постхирургических поражений тканей, а также диабета и многих других заболеваний, связанных с нарушением функций внутренних органов [1-3]. Во всех перечисленных случаях наблюдаемые положительные биологические и медицинские последствия возникают в ответ на облучение пациента лазером с известной частотой излучения, и потому вполне разумной воспринимается трактовка наблюдаемого терапевтического эффекта как организменного ответа на прямое поглощение энергии лазерного излучения „молекулами, участвующими в энергетическом цикле клетки, благодаря чему происходит его нормализация“ [5].

Новые эффекты в биомедицинских применениях лазерного излучения были получены в работах первых авторов настоящей работы [6,7]. Ими в экспериментах, проводимых в течение десяти лет, изучался эффект опосредованного воздействия излучения гелий-неонового лазера. В опытах на лабораторных животных и клеточных культурах $\mathrm{He}-\mathrm{Ne}$-лазер с мощностью $2 \mathrm{~mW}$ и длиной волны $632.8 \mathrm{~nm}$ облучает клеточную культуру или препарат, содержавший свежевыделенную ткань новорожденного крысенка (мышонка) (мозг, селезенка, костный мозг), что вызывает повышение резистентности клеточных культур или организмов групп животных, располагаемых рядом с облучаемым препаратом, в отношении целого ряда токсичных воздействий и заболеваний. В связи с научной и практической значимостью результатов, полученных в экспериментах [6,7], представляется крайне важным проведение экспериментальных исследований по установлению физических параметров излучений, вызывающих наблюдаемое протекторное действие на биообъекты, а также развитие физической модели процесса.

В связи с отсутствием каких-либо предварительных данных о частотном диапазоне протекторного излучения, воздействующего на биологические объекты, а 
также в связи с необходимостью защиты экспериментаторов от действия излучения с неизвестным биологическим эффектом, первым этапом экспериментальных исследований явилось изучение возможности экранирования протекторных излучений облучаемых препаратов пассивными экранами.

\section{Экспериментальные условия}

Схема биологического эксперимента с получением протекторного излучения и оценки его действия представлена на рис. 1. В качестве источника первичного излучения использовался одномодовый частотно-стабилизированный гелий-неоновый лазер, работающий в постоянном режиме с мощностью порядка $2 \mathrm{~mW}$ и длиной волны излучения $\lambda=632.8 \mathrm{~nm}$. На расстоянии $100 \mathrm{~mm}$ от выходного окна лазера располагается предметный столик, на котором непосредственно на пути лазерного луча размещается биологический препарат (первичная мишень), обычно в виде тонкого полупрозрачного слоя ткани или клеточной культуры, зажатого между двумя предметными стеклами. Поглощение препаратом излучения лазера в эксперименте составляет в среднем $40-60 \%$.

Биологическим детектором протекторного излучения, генерируемого первичной мишенью, является препарат клеточной культуры или лабораторные животные. Биологический детектор (вторичная мишень) располагался в одной плоскости с предметным столиком лазерной установки. Расстояние между ними может варьировать от $20 \mathrm{~cm}$ до нескольких десятков метров. При исследовании экранирующих эффектов биологическая мишень могла помещаться за непрозрачной диэлектрической стенкой или в одном из экранов, описанных ниже.

Для предварительного исследования экранировки протекторного излучения были использованы три типа экранов: диэлектрическая стенка размером $5 \times 6 \mathrm{~m}$ и толщиной $200 \mathrm{~mm}$, толстостенный герметичный контейнер из магнитомягкого материала (безуглеродистое железо) с толщиной стенки $15 \mathrm{~mm}$ и герметичная камера из нержавеющей немагнитной стали размерами $1000 \times 300 \times 300 \mathrm{~mm}$ с толщиной стенки $2.5 \mathrm{~mm}$. Для предварительного определения диапазонов экранировки используемых экранов применялись беспроводные приемники излучения, работающие от автономных источников питания и передающие наружу данные акустически.

\section{Экспериментальные результаты}

\section{Проверка экранирующей способности и диапазонов экранировки используемых экранов}

Экранировка высокочастотных электромагнитных полей (ЭМП) является непростой задачей; несмотря на ее огромную практическую важность в литературе

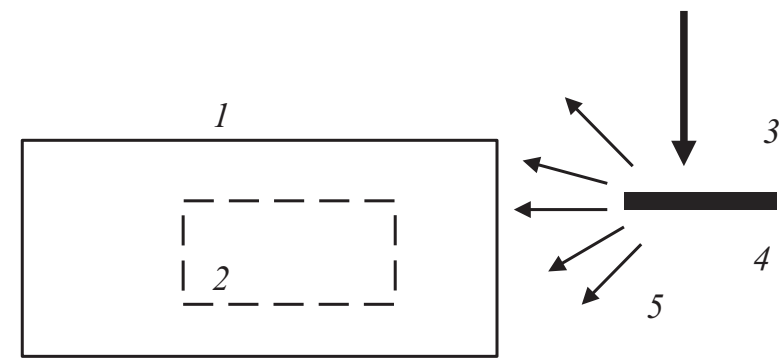

Рис. 1. Схема эксперимента: $1-$ сплошной металлический экран, 2 - клетка с лабораторными животными, 3 - излучение $\mathrm{He}-\mathrm{Ne}$-лазера, 4 - биологическая ткань (препарат преобразователь излучения), 5 - вторичное биологически активное излучение.

по-прежнему имеются разночтения в отношении базовых физических процессов, приводящих к экранировке $[8,9]$. Ключевыми факторами являются сплошность экрана или, наоборот, наличие в нем отверстий, а также толщина экрана и его геометрические размеры в сравнении с длиной волны излучения. Для низкочастотного излучения в индукционной зоне важным также является доминирование магнитной или электрической составляющей. В условиях, когда материал экрана достаточно сильно понижает интенсивность поля (на 40-60 dB и более), каждое отверстие в экране, даже намного меньшее длины волны, становится источником проникновения поля. В целом полный расчет экрана требуемой формы является очень ресурсоемким даже при использовании современных компьютеров, причем его результаты критичны в отношении точности задания характеристик материала экрана, которые с учетом значимой роли скин-эффекта обычно известны плохо. В проводимом эксперименте использовались имеющиеся герметичные камеры из магнитного и немагнитного материлов, и их экранирующая способность проверялась путем помещения внутрь беспроводных приемников излучения, работающих от автономных источников питания и передающих наружу звуковые сигналы. Это накладывало ограничения на частотные диапазоны ЭМП, так как не для каждого диапазона имеются соответствующие высокочувствительные приемники.

Эксперименты показали, что диэлектрическая стенка практически не экранировала сигналы с частотой ниже $10 \mathrm{THz}(30 \mu \mathrm{m})$ и почти полностью подавляла их в диапазоне длин волн короче $10 \mu \mathrm{m}$, т.е. выше $30 \mathrm{THz}$. Экран из магнитомягкого материала понижал интенсивность низкочастотных магнитных полей на $100-120 \mathrm{~dB}$, экранировал электромагнитные поля с частотой порядка $1 \mathrm{GHz}$ на $50-60 \mathrm{~dB}$, до $100-120 \mathrm{~dB}$ при $10 \mathrm{GHz}$ и практически полностью подавлял его на более высоких частотах. Камера из нержавеющей стали не экранировала магнитные поля, но обеспечивала защиту от ЭМП на уровне 60-70 dB при $1 \mathrm{GHz}$ до практиче- 
ски полного подавления излучения при частотах выше $10 \mathrm{GHz}$.

\section{Экранировка протекторного излучения с помощью тех же экранов}

В экспериментах по проверке экранирования протекторного излучения биологических тканей в качестве критерия экранирования использовалось число выживших клеток биологической мишени - культуры клеток или число лабораторных животных.

Поскольку контейнер из магнитомягкого железа имел небольшие размеры, проверка его экранирующего действия проводилась на клеточной культуре, в качестве которой использовалась культура Hek (эмбриональная почка человека). Эксперимент проводился в три последовательных этапа. На первом этапе в необлученный препарат клеточной культуры Hek однократно вводили стауроспорин в концентрации $10 \mu \mathrm{mol} / 1$, что приводило к резкому снижению жизнеспособности клеток культуры: через двое суток после введения число погибших клеток достигало 47.4-59.2\%. На втором этапе аналогичный препарат той же клеточной культуры подвергали облучению протекторным излучением по схеме, представленной на рис. 1. Для этого его размещали на расстоянии $20 \mathrm{~cm}$ от предметного столика лазерной установки, где в качестве облучаемой лазером биологической субстанции использовалась та же клеточная культура, помещенная между предметными стеклами. Облучение проводилось в течение $10 \mathrm{~min}$, после чего в облученный препарат однократно, в той же дозе вводился стауроспорин. Эксперимент проводился дважды: относительное число погибших клеток составило в первом эксперименте $27.6 \%$, а во втором - 5\%. Третий этап состоял в том же облучении, но с экранировкой биологической мишени. Для этого клеточную культуру, используемую в качестве биологического детектора протекторного излучения, экранировали от действия протекторного излучения, генерируемого той же культурой, помещенной под лазерным лучом, либо помещая между ними непрозрачную диэлектрическую стенку, либо помещая культурудетектор в толстостенный магнитный контейнер. При этом сохранялось и расстояние облучаемой культуры от источника излучения $-20 \mathrm{~cm}$, и время облучения. После добавления к культуре-детектору стауроспорина в той же концентрации относительное число погибших клеток в первом эксперименте составило 12.8\%, а во втором всего 5.6\%, т.е. протекторный эффект имеет место на том же уровне, что и без применения экранов. Таким образом, ни один из использованных экранов не привел к снижению эффективности протекторного действия вторичного излучения.

Экран из нержавеющей стали, большой по объему, позволил провести эксперименты на животных. Подкожное введение беспородным мышам-самцам фосфакола в концентрации $0.23-0.25 \mathrm{mg} / \mathrm{kg}$ приводило к быстрому развитию клинической картины интоксикации и 70\%

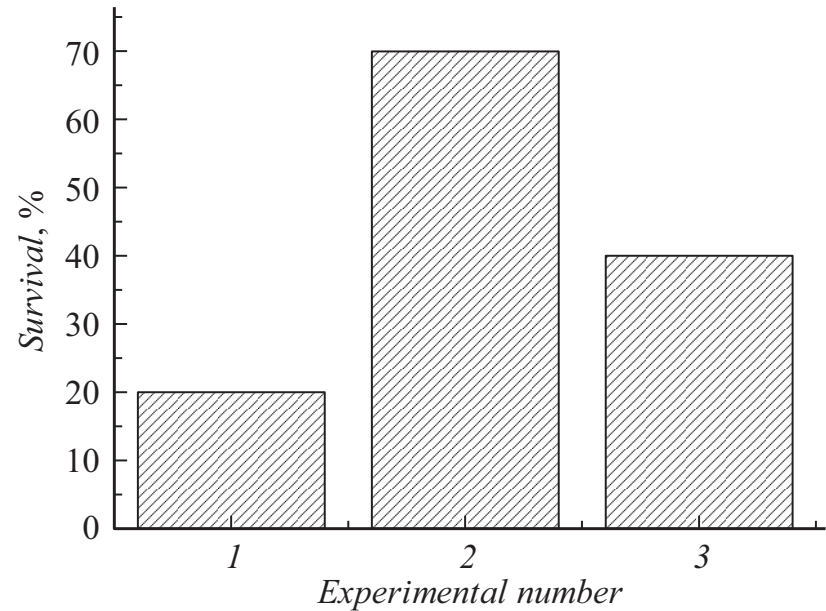

Рис. 2. Число лабораторных мышей, выживших после введение фосфакола в концентрации $0.23-0.25 \mathrm{mg} / \mathrm{kg}$ : 1 - без облучения, 2 - после облучения, 3 - после облучения через экран.

летальности в первые 15-30 min после введения. В случае лазерного облучения полупрозрачного препарата, содержащего свежевыделенную ткань гипоталамических структур головного мозга новорожденного мышонка (Р1-4), в опытной группе, расположенной на расстоянии $50 \mathrm{~cm}$ от источника вторичного излучения, было показано формирование заметной устойчивости к токсическому действию фосфакола, вводимого в тех же концентрациях: летальность в этой группе составила только 20\%. Диэлектрическая стенка в этом случае не снижала эффект протекторного действия вторичного излучения на лабораторных животных. Также на него не влияло и расстояние между источником протекторного излучения и его биологической мишенью: увеличение расстояния с $0.5 \mathrm{~m}$ до примерно $20 \mathrm{~m}$ не приводило к заметному снижению эффекта. Однако помещение опытной группы животных в экран из нержавеющей стали во время лазерного облучения препарата, содержащего ту же нейрональную ткань, приводило к увеличению летальности в этой группе до 40\%, что свидетельствует о частичной экранировке протекторного излучения в данном случае. Результаты эксперимента представлены на рис. 2.

Во всех случаях протекторный эффект достигался только при использовании свежеприготовленного препарата. При попытке использования плацебо либо при повторном использовании препарата эффекта не наблюдалось.

\section{Обсуждение и физическая модель}

Полученные экспериментальные результаты показывают, что наблюдаемый эффект ни в коей мере не может быть отнесен за счет рассеянного первичного лазерного излучения: и непрозрачная диэлектрическая стенка, и 
металлические экраны полностью подавляют оптическое и близкое ИК излучение. Таким образом, указанные эффекты могут быть вызваны только вторичным электромагнитным излучением, которое генерируется в результате взаимодействия лазерного луча с облучаемой биологической мишенью, в нашем случае - тканями тела или клетками клеточной культуры. Это излучение, названное нами протекторным, воспринимается биологическими мишенями - лабораторными животными и клеточными культурами, формируя описанный выше организменный ответ. Оно является низкоинтенсивным и может иметь очень сложный спектральный и фазовый состав. Главной причиной того, что до настоящего времени попытки зарегистрировать это излучение физическими методами не увенчались успехом, является полное отсутствие информации о распределении излучения в пространстве и во времени, его частотном диапазоне и предполагаемой интенсивности.

Эксперименты с экранами показывают, что рассматриваемое излучение заведомо не лежит в области видимого или ближнего ИК диапазона. Не очень вероятным представляется и то, что оно относится к области низкочастотных магнитных колебаний: ЭМП этого диапазона было бы гораздо сильнее подавлены экраном из магнитомягкого материала, чем камерой из нержавеющей стали, хотя в эксперименте именно экран третьего типа в большей степени ослабляет протекторные воздействия, чем экран второго типа. Важным при этом является то, что экран третьего типа был существенно бо́льшим по размеру, а это значимо в области высоких частот, когда длина волны излучения становится сравнимой или меньше геометрических размеров экрана. Если в экране отсутствуют отверстия, то, абстрагируясь от деталей, можно считать, что ЭМП спадает внутри экрана от его стенок к центру по экспоненциальному закону, причем показателем экспоненты является отношение расстояния от стенки к длине волны.

Из сравнения диапазонов экранировки и высказанных выше представлений следует, что наилучшим кандидатом на роль протекторного (вторичного) излучения является излучение, лежащее в диапазоне единиц и десятков GHz. Именно для него преимущества геометрически большого экрана выражены перед экраном меньших размеров, а сорт металла и его магнитные свойства на таких частотах особого значения не имеют.

В настоящее время отсутствует общепринятый механизм взаимодействия лазерного излучения с биологическими объектами, который мог бы описать наблюдаемые лечебные и протекторные воздействия. В уже упоминавшемся предложенном В.А. Овсянниковым [3] механизме отсутствует описание того, что он называет „энергетическим циклом клетки“, вследствие чего этот механизм так и не превратился в полноценную биофизическую теорию и не может быть использован (кроме названия) для описания молекулярного механизма терапевтического действия лазерного облучения.
Мы считаем, что основной причиной, по которой пока не предложен механизм взаимодействия лазерного излучения с живыми клетками, является недостаточное представление об объекте этого взаимодействия, функционирующем в живом. В соответствии с развиваемыми нами представлениями [10] в живом функционируют объединенные системы типа биополимер и окружающая его водная среда, образующая с ним неоднородную гидрофильно-гидрофобную структуру. Развиваемая далее модель биологического действия излучения в оптическом диапазоне построена на суммировании решений ряда физических задач, выполненных в биоматематике $[11,12]$ и в обобщенной кристаллографии [13]. Эти решения признаны мировой наукой и экспериментально проверены [14]. Из них следует, что, во-первых [11], внешняя энергия различных видов, доставленная к биополимеру живой клетки и вызвавшая колебания его цепей, самолокализуется на атомных группах - осцилляторах, являющихся частью цепи биополимеров. Результатом этой самолокализации является преобразование первичной энергии в форму нелинейных волн - солитонов. Их энергия в свою очередь определяется собственными частотами атомных осцилляторов биополимера, на которых она самолокализовалась, т.е. является специфически зависимой от молекулярных свойств биополимера-преобразователя. Солитоны, свободно транспортирующиеся по цепям биополимеров, способствуют структурированию воды вблизи него [12], в результате чего на гидрофильных центрах биополимера образуются энергонапряженные модульные одномерные структуры из молекул $\mathrm{H}_{2} \mathrm{O}$. При этом образующиеся фрактальные квазикристаллические модули находятся в состоянии полной связанности с жидкой фазой воды [13], и их длительное существование поддерживается транспортирующимися по ним солитонами [15]. Энергии солитонов, образованных в колебательных процессах биополимеров и молекулярноводных структурах живых клеток, лежат в широком диапазоне частот от дальнего ИК до радиочастотного; при разрушении биополимеров или образования на них дефектов эти солитоны способны излучаться в окружающую среду, формируя вторичное биологически активное излучение. Спектральный и фазовый составы этого излучения должны зависеть от сорта ткани, осуществляющей преобразование, но в первом приближении не зависят от природы первичного излучения, что и наблюдается в эксперименте. В этом эксперименте $\mathrm{He}-\mathrm{Ne}$-лазер, создавая значительную плотность мощности порядка $10 \mathrm{~W} / \mathrm{cm}^{3}$, вызывает активную накачку биополимеров ткани, сопровождающуюся их деструкцией. В результате создается плотность вторичного излучения, в сотни раз превышающая таковую для реально живущего существа. За время эксперимента, длящегося $\sim 20 \mathrm{~min}$, ткань первичной мишени полностью деградирует и перестает работать как преобразователь энергии.

Отметим, что схожие результаты достигаются, когда в лазерной терапии облучаются не ткани, требующие 
лечебного воздействия (опухоль, воспаление), а другие, например, более доступные здоровые ткани, а выздоровление достигается за счет организменного ответа. В опытах, представленных в настоящей работе, излучение вызывало положительный, стимулирующий и протекторный эффекты; однако оно может продуцировать и супрессорный и даже тератогенный эффекты. В связи с этим важным вопросом представляется защита персонала от подобного излучения.

\section{Краткие результаты и выводы}

Таким образом, проведенные эксперименты по экранированию клеточных культур и животных, выступающих в роли биологического индикатора (детектора) результата лазерного облучения первичной биологической мишени, показали, что:

1. Наблюдаемое в эксперименте сильное протекторное действие на лабораторных животных и клеточные культуры, расположенные вблизи тканевой мишени, облучаемой лучом $\mathrm{He}-\mathrm{Ne}$-лазера, и выражающееся в данном случае в повышении стойкости токсикантам, оказывает именно вторичное электромагнитное излучение, генерируемое облучаемой тканью или культурой клеток.

2. Вторичное протекторное излучение является специфическим продуктом облучаемой первичной биологической мишени, имеет высокую плотность и воздействует именно на клетки и ткани, аналогичные первичной мишени. Для получения заданного биологического эффекта должна использоваться специфическая для этого эффекта ткань первичной мишени [3].

3. Незамкнутый экран (диэлектрическая стенка), полностью экранирующая первичное излучение лазера, не оказывает влияния на наблюдаемый протекторный эффект, а использованные замкнутые металлические толстостенные экраны несколько понижают его выраженность, но не обеспечивают полного подавления.

4. Физическая модель движения энергии в живой системе, основанная на представлениях об образовании солитонов в биомолекулярно-водной среде, качественно описывает закономерности образования вторичного излучения.

5. Данные об экранировке в совокупности с модельными представлениями заставляют отнести вторичное излучение к КВЧ, СВЧ и радиочастотному диапазону частот от сотен $\mathrm{GHz}$ и ниже.

\section{Список литературы}

[1] Москвин С.В. Основы лазерной терапии. Серия „Эффективная лазерная терапия“. М.-Тверь: Изд-во Триада, 2016. $896 \mathrm{c}$.

[2] Лазерная терапия в лечебно-реабилитационных и профилактических программах: клинические рекомендации. М.: 2015. $80 \mathrm{c}$.

[3] Овсянников В.А. // Труды медицинского семинара „Современные медицинские технологии“. Адлер. 2002. С. 31-33.
[4] Мантейфель В.М., Кару Т.Й. // Изв. РАН. Сер. биол. 2005. № 6. C. $672-683$.

[5] Овсянников В.А. // Вопросы онкологии. 1986. Т. 32. № 9. C. $72-74$.

[6] Кокая А.А., Козяков В.П., Мухина И.В. // Вестн. Росс. Воен.-мед. акад. 2012. № 40. С. 163-168.

[7] Кокая А.А., Ведунова М.В., Митрошина Е.В., Козяков В.П., Мухина И.В. // Вестн. Росс. Воен.-мед. акад. 2013. № 42. C. 109-115.

[8] Шапиро Д.Н. Основы теории электромагнитного экранирования. Л.: Энергия, 1975. $112 \mathrm{c.}$

[9] Конторович М.И. // ЖТФ. 1939. Т. 9. Вып. 24. C. $2195-2210$.

[10] Галль Л.Н., Галль Н.Р. // Биофизика. 2009. Т. 54. № 3. C. $563-574$.

[11] Давыдов А.С. Солитоны в молекулярных системах. Киев: Наукова думка, 1988. 304 с.

[12] DelGuidance E., Doglia S., Milani M., Vitiello G. // Nucl. Phys. B. 1985. Vol. 251. P. 375-400.

[13] Бульенков Н.A. // Биофизика. 2005. Т. 50. № 5. С. 620-664.

[14] Alexan D.M., Krumhansl J.A. // Phys. Rev. B. 1986. Vol. 33. P. $7172-7185$.

[15] Галль Л.Н. Физические принципы функционирования материи живого организма. СПб.: Изд. СПбПУ им. Петра Великого, 2014. 400 c. 